\title{
Vibroacoustic Stimulation
}

National Cancer Institute

\section{Source}

National Cancer Institute. Vibroacoustic Stimulation. NCI Thesaurus. Code C114085.

A fetal stimulation technique that uses vibratory sound applied to the maternal abdomen to elicit a fetal heart rate acceleration response before or during labor. 